ảnh hỗ trợ trong phòng mổ và chỉ được chỉ định trong những trường hợp BHSS bệnh nhân tương đối ổn định. Chỉ định sản khoa cho tắc động mạch chọn lọc được báo cáo chủ yễu là do tổn thương đường sinh dục và đờ tử cung với tỉ lệ thành công lần lượt là $90 \%$ và $100 \%$ [8]. Hiện tại ở Bệnh viện Từ Dũ chưa áp dụng phương pháp này vào phác đồ điều trị BHSS.

Sau thất bại với các biện pháp điều trị ít xâm lấn ban đầu, cắt tử cung cấp cứu là biện pháp điều trị nên được tiến hành ngay, đặc biệt nếu BHSS nặng có liên quan đến nhau bong non hoặc võ tử cung. Trong nghiên cứu của chúng tôi, tất cả các ca trước khi cắt tử cung cấp cứu đều được sử dụng các thuốc hố trợ gò tử cung (Oxytocin, Misoprostol, Ergotamin, Duratocin và Endoprost) và cầm máu (Transamic), có $5 \mathrm{ca}$ được đă̆t bóng chèn lòng tử cung. Tất cả 7 đều được cắt tử cung toàn phần. Việc cắt tử cung cấp cứu trong BHSS bán phần gần đây được gợi ý vì kĩ thuật phẫu thuật nhanh hơn và ít biển chứng tổn thương cơ quan lân cận hơn [2]. Tuy nhiên nó có nhiều nguy cơ vì chảy máu ở vùng cổ tử cung vẫn có thể còn đang tiếp diễn. Các biến chứng có thể liên quan đến phẩu thuật cắt tử cung cấp cứu bao gồm: tổn thương bàng quang, niệu quản, nhiễm trùng, xuất huyết và tử vong mẹ [2].

\section{KẾT LUÂ̂N}

Phụ nữ bị BHSS nặng tuy chiếm tỉ lệ nhỏ nhưng là một nhóm bệnh cảnh quan trọng, góp phần lớn vào gánh nặng bệnh do BHSS. Tuy đã có nhiều tiến bộ trong kĩ thuật y tế và phẫu thuật nhưng phẫu thuật cắt tử cung cấp cứu vẫn là phương pháp điều trị quan trọng trong BHSS nặng không đáp ứng điều trị ban đầu.

\section{TÀI LIÊU THAM KHẢO}

1. A. Mehrabadi, J. A. Hutcheon, L. Lee, R. M. Liston, and K. S. Joseph, "Trends in postpartum hemorrhage from 2000 to 2009: A populationbased study," BMC Pregnancy Childbirth, 2012.

2. J. Smith and H. A. Mousa, "Peripartum hysterectomy for primary postpartum haemorrhage: Incidence and maternal morbidity," J. Obstet. Gynaecol. (Lahore)., 2007.

3. L. T. Nyfløt et al., "Risk factors for severe postpartum hemorrhage: A case-control study," BMC Pregnancy Childbirth, 2017.

4. A. S. Oberg, S. Hernandez-Diaz, K. Palmsten, C. Almqvist, and B. T. Bateman, "Patterns of recurrence of postpartum hemorrhage in a large population-based cohort," in American Journal of Obstetrics and Gynecology, 2014.

5. S. L. Clark, S. Y. Yeh, J. P. Phelan, S. Bruce, and R. H. Paul, "Emergency hysterectomy for obstetric hemorrhage," Obstet. Gynecol., 1984.

6. H. Camuzcuoglu, H. Toy, M. Vural, F. Yildiz, and H. Aydin, "Internal iliac artery ligation for severe postpartum hemorrhage and severe hemorrhage after postpartum hysterectomy," ]. Obstet. Gynaecol. Res., 2010.

7. E. El-Hamamy, A. Wright, and C. B-Lynch, "The B-Lynch suture technique for postpartum haemorrhage: A decade of experience and outcome," Journal of Obstetrics and Gynaecology. 2009.

8. J. J. Merland et al., "Place of emergency arterial embolisation in obstetric haemorrhage about 16 personal cases," in European Journal of Obstetrics and Gynecology and Reproductive Biology, 1996.

\title{
TẠO HÌNH TAI NHỎ SỚM, MộT THÌ BẰNG KHUNG SỤN NHÂN TẠO VÀ TỰ THÂN CÓ NộI SOI HỖ TRỢ TẠI HÀ NộI
}

\section{Nguyễn Hồng Hà*, Trần Thị Thanh Huyền*, Nguyễn Thu Hằng*, Nguyễn Thị Hương Giang*, Ngô Hải Sơn*}

\section{TÓM TẮT}

Khuyết vành tai là một tổn thương phức tạp, nó có nhiều dạng khác nhau từ khuyết một phần hoắc toàn bộ vành tai do bẩm sinh. Cấu trúc giải phẫu đă̆c biệt của tai cũng như hình thể 3 chiều của nó khiến cho việc tao hình tai luôn đặc biệt khó khăn. Chúng tôi

\footnotetext{
*Bệnh viện Việt Đức, Hà Nội

Chịu trách nhiệm chính: Nguyễn Hồng Hà

Email: nhadr4@gmail.com

Ngày nhận bài: 30/11/2020

Ngày phản biện khoa học: 15/12/2020

Ngày duyệt bài: 22/12/2020
}

muốn báo cáo kết quả phẫu thuật tạo hình tai nhỏ sớm, một thì bằng khung sụn nhân tạo Medpor và sụn sườn tự thân tại Hà Nội, Việt Nam. Để gia tăng tị lệ thành công và giảm biến chứng phẫu thuật, việ̂́c bóc tách vạt cân thái dương đỉnh được thực hiện bắng kỹ thuật nội soi chỉ với 1 lỗ duy nhất. Trước mổ bệnh nhân được kiểm tra thính lực để có phương án điều trị hỗ trợ nghe phối hợp. Sau mổ tất cả các bệnh nhân và gia đình đều hài lòng với kết quả ngay sau phẫu thuật. Với tỉ lệ biến chứng thấp, kết quả thâm mỹ và mức độ hài lòng cao của người bênh khiến các kỹ thuật này đã̉ mang đến những lựa chọn tối ưu trong điêu trị dị tật và khuyết hổng vùng tai.

Tư khóa: Tạo hình tai, tai nhỏ bẩm sinh, khuyết tai, Medpor ear, Polyethylene Implant. 


\section{SUMMARY \\ EARLY AND ONLY ONE STAGE RECONSTRUCTION OF MICROTIA BY MEDPOR IMPLANT AND RIB CARTILAGE WITH ENDOSCOPIC ASSISTED TECHNIQUE AT HANOI}

Ear reconstruction still a big challenge for Plastic surgeon. The complex anatomy of the external ear and the necessity to provide good projection and 3D symmetry make this reconstruction particularly difficult. The aim of this paper is to report our result of early and only one stage ear reconstruction by Medpor Polyethylene implant and autologous costal cartilage with endoscopic assisted technique at $\mathrm{Ha} \mathrm{Noi}$, Viet Nam. To archive the best aesthetic result and diminue complication rates, all temporoparietal fascia flap was harvested by single - incision endoscopic technique. Before surgery patients has been check with audiologist specialists to determine the combination treatment for hearing loss. Results postoperative have been considered satisfactory by all patients and their family. Low morbidity, the good results obtained and a high rate of patient satisfaction make this techniques become ideal choices for reconstruction surgery of the ear.

Keywords: Ear reconstruction, Microtia, Medpor, Polyethylene Ear Implant

\section{I. ĐẶT VẤN ĐỀ}

Phẫu thuật tạo hình các tổn khuyết vành mắc phải hoặc do dị tật tai nhỏ bẩm sinh có thể được chia thành 2 nhóm lớn dựa trên việc sử dụng khung sưn tự thân hoặc khung sụn nhân tạo. Các kỹ thuật kinh điển trước đây dựa trên khung sụn sườn tự thân với khoảng 2 đến 4 thì phẫu thuật. Do đó với dị tật tai nhỏ bẩm sinh, các bé thường phải chờ tới 8 đến 12 tuổi mới có khung sụn đủ lớn để tạo hình tai mới. Từ những năm 1990 GS Reinisch tiên phong trong viêc tái tạo tai sớm 1 thì cho các bệnh nhi ở độ tuổi 45 tuổi bằng khung sụn nhân tạo Polyethylene. Điểm mấu chốt để tằng tỉ lệ thành côngcủa tạo hình một thì̀ cần có được một lớp cân da mỏng, che phủ tốt khung sụn với ít lần phấu thuật nhất. Vạt cân thái dương đỉnh (TDĐ) là sự lựa chọn tối ưu để giảm thiểu các biến chứng liên quan đến lộ khung sụn hoặc chất liệu nhân tạo $[4,7,8]$.

Trước đây để lấy được cân thái dương đỉnh các phẫu thuật viên thường phải rạch 1 đường rạch hình chữ $Y$ hoặc $T$ hơn $20 \mathrm{~cm}$ trên da đầu của trẻ. Phương pháp này thường để lại sẹo xấu và biến chứng rụng tóc mất thẩm mỹ. Kỹ thuật lấy vạtcân TDĐ có nội soi hỗ trợ giúp quan sát các mạch máu nuôi vạt một cách chính xác hơn, đảm bảo tối đa sức sống của vạt cho phép che phủ toàn bộ khung sụn tự thân và nhân tạo làm gia tăng tỉ lệ thành công của phẫu thuật 1 thì $[2,4]$. Ơ Việt Nam, chúng tôi chưa thây có một tài liệu nào thông báo kết quả tạo hình tai một thì bằng khung sụn nhân tạo Polyethylene cũng như chưa hề có tác giả nào tiến hành lấy cân thái TDĐ dưới nội soi hỗ trợ. Trong bài báo này, chúng tôi mô tả kỹ thuật tạo hình tai một thì bằng sụn sườn tự thân và nhân tạo, được che phủ bằng vạt cân thái dương đỉnh với hỗ trợ của kỹ thuật nội soi với một đường rạch duy nhất.

\section{II. ĐỐI TƯỢNG VÀ PHƯƠNG PHÁP NGHIÊN CỨU}

2.1. Đối tượng: Tiến hành trên các bệnh nhân (BN) tai nhỏ bẩm sinh hoặc mất tai do chấn thương được tạo hình tai một thì bằng sụn sườn tự thân và nhẩn tạo Polyethylene từ tháng 6/2018 đến 9/2020. Các bệnh nhân bị dị tật tai nhỏ 2 bên hoặc có biểu hiện nghe kém được chỉ định khám đo thính lực để có phương án phối hợp điều trị nhằm tăng cường sức nghe cho trẻ.

2.2. Phương pháp: Khung sụn sườn tự thân được điêu khắc từ sụn sườn $6,7,8,9$ theo kỹ thuật của Firmin và được điều chỉnh kích thước để phù hợp với tai đối diện. Khung sụn nhân tạo sử dụng là khung Polyethylene được hàn ghép tại phòng mổ theo kỹ thuật mô tả bởi Reinisch. Tất cả các khung sụn được che phủ bằng vạt cân thái dương đỉnh được bóc bằng kỹ thuật nội soi với một đường rạch duy nhất (Hình 2). Chỉ với đường rạch da 3-4 cm ngang theo đường chân tóc trên ống tai ngoài, với sự hố trợ của nội soi, chúng tôi có thể bóc được một vạt cân TDĐ dài $10 \mathrm{~cm} \times 9 \mathrm{~cm}$ (Hình 2) với đầy đủ 2 nhánh của động mạch thái dương nông và cả vòng nối quặt ngược.

Đánh giá kết quả dựa vào khả năng sống của vạt da, da vá, hình thể tai tạo hình, khả năng sống tồn tại của khung sụn trong người bệnh nhân cũng như kết quả thẩm mỹ và mức độ hài lòng của bác sĩ, gia đình và người bệnh.

Các biến chứng được chia làm 2 loại, biến chứng nặng như nhiễm trùng, lộ khung sụn, chảy máu, hoại tử vạt dẫn đến mất toàn bộ khung sụn, toàn bộ vạt phải mổ lại để thay khung mới hoặc làm vạt mới hay chấp nhận tháo bỏ khung sụn. Các biến chứng nhẹ như nhiễm trùng nông, lộ khung sụn, hoại tử vậ đầu xa kích thước nhỏ chỉ cần can thiệp tại chỗ mà vẫn giữ nguyên được khung sụn

\section{KẾT QUẢ NGHIÊN CỨU}

Từ tháng $6 / 2018$ đến $9 / 2020$ có 45 BN tai nhỏ và mất tai do chấn thương, độ tuổi từ 3,5 tuổi đến 50 tuổi, được tạo hình tai toàn bộ một thì, trong đó $14 \mathrm{BN}$ sử dụng sụn sườn tự thân tuổi 9 đến 22 tuổi và 31 BN dùng khung sụn nhân tạo Polyethylenetuổi từ 3,5 tuổi đến 50 tuổi, trong đó có tới 12 bệnh nhân dưới 6 tuổi được phẩu thuật sớm trước khi đi học. Tỉ lệ 
Nam: Nữ là 1,4: 1. Nguyên nhân dị tật tai nhỏ bẩm sinh là 42 (có $4 \mathrm{BN}$ bị cả 2 tai) và mất tai do tai nan là $3 \mathrm{BN}$.

Tất cả cân thái dương đỉnh đều sống toàn bộ ngay sau khi bóc vạt, các cung mạch được bảo tồn đủ cả nhánh trán và nhánh đỉnh của ĐM thái dương (Hình 2). Sau 2 tuần tháo khuôn tất cả các vạt cân đều sống tốt. Sau mổ không có BN có biến chứng lớn đến mức phải tháo bỏ khung sụn. Nhóm 14 BN khung sụn tự thân có 1 trường hợp nhiễm trùng nông điều trị bằng kháng sinh tĩnh mạch đáp ứng tốt không xảy ra biến chứng nào tiếp theo. Một $\mathrm{BN}(7,1 \%)$ có lộ khung sụn đầu xa khoảng $3 \mathrm{~mm}$ nhưng sau đó tổ chức hạt tự mọc lên được. Nhóm 31 khung sụn nhân tạo có 5 trường hợp $(16,1 \%)$ bị lộ khung sụn kích thước từ 3-7mm chỉ cần chuyển vạt tại chỗ che phủ mà không hề phải thay hay tháo bỏ khung sụn. Trong đó có 2 trường hợp có dấu hiệu nhiễm trùng sau mổ điêu trị kháng sinh ổn định.

Theo dõi sau mổ tất cả khung sụn ổn định, không hề có biến chứng lộ hay vỡ khung sụn. Da vá sống tốt trên vạt cân, có thể trượt và di động trên khung sụn. Khung sụn tự thân có độ nhô thấp hơn so với khung sụn nhân tạo. Tất cả bệnh nhân và gia đình đều hài lòng với kết quả tai tạo hình. Về thẩm mỹ thì tai tạo hình bằng khung sụn nhân tạo có đường nét rõ ràng và thẩm mỹ hơn so với khung sụn tự thân (Hình 4).

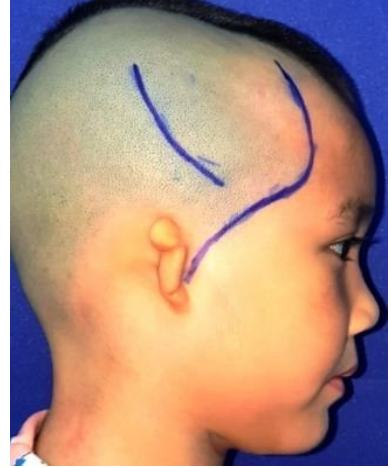

Hình 1. Bệnh nhân tai nhỏ (microtia) 5 tuổi.

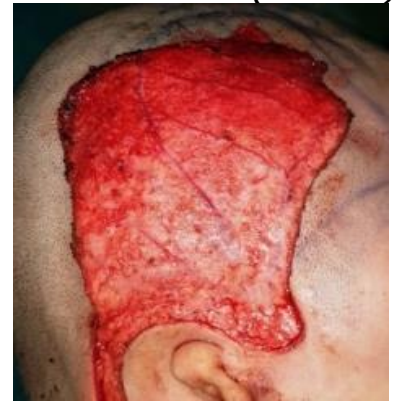

Hình 2. Bóc tách nôi soi đảm bảo cân thái dương đỉnh với đầy đủ các cung động tĩnh mạch

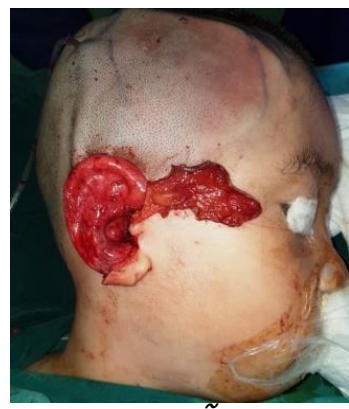

Hình 3. Da đầu trên chồ cho vạt không hề có sẹo do ứng dung nội soi một lố.

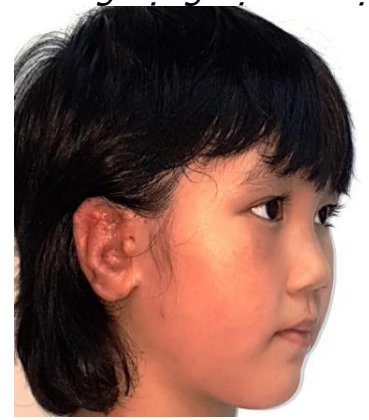

Hình 4. Sau mồ 6 tháng, kêt quả thẩm mỹ tôt, không để lại sẹo da đầu, tóc mọc tôt, chi với 1 lần phẫu thuật.

\section{BÀN LUẬN}

Cho đến nay hầu hết tất cả các phương pháp tạo hình tai kinh điển theo Brent, Nagata, Firmin đều tiến hành theo nhiều giai đoạn, từ 2 đến 4 giai đoạn. Chất liệu tạo hình là sụn sườn tự thân của $B N$. Chính vì vậy tất cả các tác giả đều khuyên rằng nên đợi đến độ tuổi 10 đến 12 tuổi, khi có lồng ngực đủ lớn mới tiến hành phẫu thuật thì đâu. Việc chờ đợi này gây ảnh hưởng tâm lý nặng nề cho các bệnh nhi và gia đình nhất là khi các bé đến tuổi học đường.

Từ những năm 1990 Reinish, đã đi tiên phong trong nghiên cứu tạo hình tai sớm cho trẻ $3-5$ tuổi bằng khung sụn nhân tạo Polyethylene chỉ với 1 lần phẫu thuật . Sử dung được khung sun nhân tạo tránh được các tổn thương lồng ngực của trè, số lần mổ ít đi, đõ vất vả cho gia đình, xã hội.Tuy nhiên cho đến nay nó vẫn là một kỹ thuật khó đòi hỏi sự khéo léo, tỉ mỉ và quá trình học tập lâu dài nên vẫn còn ít phẫu thuật viên làm chủ tốt kỹ thuật. Những ý kiến phản đối cho rằng nguy cơ lộ khung sụn, nhiễm trùng là cao. Trong những năm đầu Reinisch và cộng sự gặp tie lệ biến chứng lên tới $44 \%$ bệnh nhân lộ khung sụn và 25 vỡ khung sụn. Không ngừng cải tiến kỹ thuật giúp cho ông và cộng sự giảm được tỉ lệ biến chứng xuống thấp chỉ còn $7,3 \%$ lộ sụn và $2,7 \%$ võ khung trong 12 năm tiếp theo. Từ 
đó đến nay ông đã phẫu thuật thành công cho hàng nghìn bệnh nhân trên khẳp thế giới $[7,8]$.

Kinh nghiệm của Reinisch cho thấy muốn giảm thiểu nguy cơ lộ khung sụn nhân tạo, cần lấy được toàn bộ hai nhánh mạch trước và đỉnh vào trong vạt cũng như cả cung mạch quặt ngược đảm bảo sức sống tối đa cho vạt cân.

Ý tưởng tạo hình tai một thì bằng vạt cân thái dương đỉnh đã có từ lâu. Trước đây với các bệnh nhân có tai chân tóc gắn thấp, việc tạo hình tai kinh điển thường gặp nhiều khó khăn. Tại Mỹ Brent từ năm 1983 và Hàn Quốc 1999, Park đã báo cáo kết quả sử dụng vạt cân thái dương mổ mở trong tạo hình tai 1 thì. Cả hai tác giả đều đồng ý rằng việc mổ mở thường gây ra các biến chứng sẹo xấu và rụng tóc ảnh hưởng đến kết quả thẩm mỹ $[3,6]$.

Năm 2008 Helling và Wang lấy vạt cân thái dương đỉnh có nội soi hỗ trợ, với kích thước đủ lớn để che phủ toàn bộ khung sụn tự thân hoặc nhân tạo trong tạo hình toàn bộ vành tai 1 thì cho 9 bệnh nhân sử dụng khung sụn Medpor. Tuy nhiên để lấy bóc được vạt ở đầu xa nơi vòng đầu có sự chuyển góc ngoài đường rạch chân tóc ở thấp các tác giả đã phải rạch thêm 1 đến 2 đường rạch khoảng $2 \mathrm{~cm}-3 \mathrm{~cm}$ trên phần da đầu vùng thái dương đỉnh. Việc rạch thêm đường rạch trên vùng mọc tóc này cũng là gia tăng nguy cơ sẹo xấu và rụng tóc cho da đầu và cũng làm giảm phần nào giá trị của phương pháp nội soi $[2,4]$.

Trong nghiên cứu của chúng tôi với việc thành thạo kỹ thuật nội soi, chúng tôi nhận thây có thể dùng nội soi ở cả nhứng vùng xa của vạt nơi vòng đầu có sự gập góc mà không cần thêm bất kỳ đường rạch da nào nữa. Phương pháp này cho kết quả thẩm mỹ nhất cho da đầu.Tất cả vạt da sống tốt, chỉ có 6/45 bệnh nhân có hiện tượng lộ khung sun tự liền hoăc chỉ cần chuyên vat tại chỗ che phủ, 3 bệnh nhẩn nhiễm trùng nhẹ đáp ứng tốt với kháng sinh và không có trường hợp nào phải thay hay tháo bỏ khung sụn.

Qua tìm hiểu y văn thế giới, chúng tôi chỉ tìm được có $2-3$ tác giả báo cáo kết quả tạo hình tai 1 thì có ứng dụng bóc vạt cân thái dương đỉnh bằng nội soi với số ca khiêm tốn từ 1 đến trên dưới 10 ca lâm sàng. Qua đó chúng tôi cho rằng báo cáo này có số lượng vạt cân (45 vạt) bóc nội soi lớn nhất thế giới và trung tâm chúng tôi là một trong số rất hiếm thực hiện kỹ thuật bóc vạt cân thái dương đỉnh diện tích lớn bằng kỹ thuật nội soi chỉ với một đường rạch thẩm mỹ duy nhất $[2,4]$.

Uu điểm vượt trội của phương pháp này là chỉ với một lần mổ đã có thể tạo hình tai với đầy đủ các thành phần, giảm được 2 đến 3 lần mổ nữa cho người bệnh. Trong nhóm nghiên cứu của chúng tôi có đến 12 bênh nhi tuổi chỉ từ $3-5$ tuổi được taoo hình tai trước khi đi học. Khi cần thiết các phẫu thuật viên còn có thể phối hợp trong phẫu thuật tạo hình ống tai ngoài hoặc lẳp đặt hệ thông trợ thính góp phần phục hồi chức nghe và thẩm mỹ một cách tối đa.

\section{KẾT LUẬN}

Phẫu thuật tạo hình tai một thì bằng khung sụn tự thân và nhân tạo có che phủ bẳng cân thái dương đỉnh là một kỹ thuật khó, yêu câu quá trình đạo tạo lâu dài, phẫu thuật viên kinh nghiệm. Kết hợp các kiến thức tạo hình chuyển vat, vi phẫu thuật với ứng dụng nội soi cho phép lầy được vận cân TDĐ kích thước lớn, sức sông tốt, đảm bảo che phủ hết cả khung sụn tự thân hoặc nhân tạo. Ngay cả trên thế giới cũng mới có 2-3 trung tâm có thể thực hiện được kỹ thuật này. Với khung sụn nhân tạo cho phép thực hiện kỹ thuật sớm, một thì cho bệnh nhi nhỏ tuổi chỉ từ 3 -4 tuổi. Tạo điều kiện cho trẻ hòa nhập với cuộc sống sinh hoạt học tập một cách tốt nhất.

\section{TÀl LIỆU THAM KHẢO}

1. Trân Thị Thanhh Huyên, Bùi Mai Anh, Vũ Trung Trực, Đố Ngoc Lính, Đào Văn Giang, Nguyê̂n Hî̀ng Hà. Kểt quả tạo hình tai do khuyết tai toàn bộ tại bệnh viện Việt Đức. Y học việt nam - tháng 12 - tập 425. Tr 151 - 158, 2014

2. Biskup N., Martin MC. A True Single-Stage Reconstruction of a Projected Auricle for ConchaType Microtia Incorporating Endoscopically Harvested Temporoparietal Fascia. J Craniofac Surg. 2015 Sep;26(6):1930-2.

3. Brent, B., and Byrd, H. Secondary ear reconstruction with cartilage grafts covered by axial, random, and free flaps of temporoparietal fascia. Plast. Reconstr. Surg. 72: 141, 1983.

4. Helling ER, Okoro S, Kim G 2nd, Wang PT. Endoscope-assisted temporoparietal fascia harvest for auricular reconstruction. Plast Reconstr Surg. 2008 May;121(5):1598-60.

5. Nagata, S. Modification of the stages in total reconstruction of the auricle: Part IV. Ear elevation for the constructed auricle. Plast. Reconstr. Surg. 93: 254, 1994.

6. Park C, Mun HY. Park C, Lew DH, Yoo WM. An analysis of 123 temporoparietal fascial flaps: anatomic and clinical considerations in total auricular reconstruction. Plast Reconstr Surg 1999; 104(5): 1295-1306

7. Reinisch JF, Lewin S. Ear reconstruction using a porous polyethylene framework and temporoparietal fascia flap. Facial Plast Surg. 2009 Aug;25(3):181-9

8. Reinisch J, Tahiri Y. Polyethylene Ear Reconstruction: A State-of-the-Art Surgical Journey. Plast Reconstr Surg. 2018 Feb; 141(2): 461-470. 